\title{
Spinal stereotactic body radiotherapy following intralesional curettage with separation surgery for initial or salvage chordoma treatment
}

\author{
Dennis T. Lockney, MD, ${ }^{1,3}$ Timothy Shub, BS, ${ }^{2}$ Benjamin Hopkins, BS, ${ }^{2}$ Natalie A. Lockney, MD, ${ }^{3}$ \\ Nelson Moussazadeh, MD, ${ }^{2}$ Eric Lis, MD, ${ }^{4}$ Yoshiya Yamada, MD, ${ }^{3}$ Adam M. Schmitt, MD, ${ }^{3}$ \\ Daniel S. Higginson, MD, ${ }^{3}$ llya Laufer, MD, ${ }^{2}$ and Mark Bilsky, MD ${ }^{2}$
}

${ }^{1}$ Department of Neurosurgery, University of Florida, Gainesville, Florida; and Departments of ${ }^{2}$ Neurological Surgery, ${ }^{3}$ Radiation Oncology, and ${ }^{4}$ Radiology, Memorial Sloan Kettering Cancer Center, New York, New York

\begin{abstract}
OBJECTIVE Chordoma is a rare malignant tumor for which en bloc resection with wide margins is advocated as primary treatment. Unfortunately, due to anatomical constraints, en bloc resection to achieve wide or marginal margins is not feasible for many patients as the resulting morbidity would be prohibitive. The objective of this study was to evaluate the efficacy of intralesional curettage and separation surgery followed by spinal stereotactic body radiation therapy (SBRT) in patients with chordomas in the mobile spine.
\end{abstract}

METHODS The authors performed a retrospective chart review of all patients with chordoma in the mobile spine treated from 2004 to 2016. Patients were identified from a prospectively collected database. Initially 22 patients were identified with mobile spine chordomas. With inclusion criteria of cytoreductive separation surgery followed closely by SBRT and a minimum of 6 months of follow-up imaging, 12 patients were included. Clinical and pathological characteristics of each patient were collected and data were analyzed. Patients were divided into two cohorts-those undergoing intralesional resection followed by SBRT as initial chordoma treatment at Memorial Sloan Kettering Cancer Center (MSKCC) (Cohort 1) and those undergoing salvage treatment following recurrence (Cohort 2). Treatment toxicities were classified according to the Common Terminology Criteria for Adverse Events version 4.03. Overall survival was analyzed using KaplanMeier analysis.

RESULTS The 12 patients had a median post-SBRT follow-up time of 26 months. Cohort 1 had 5 patients with median post-SBRT follow-up time of 65.9 months and local control rate of $80 \%$ at last follow-up. Only one patient had disease progression, at 48.2 months following surgery and SBRT. Cohort 2 had 7 patients who had been treated at other institutions prior to undergoing both surgery and SBRT (salvage therapy) at MSKCC. The local control rate was $57.1 \%$ and the median follow-up duration was 10.7 months. One patient required repeat irradiation. Major surgery- and radiation-related complications occurred in $18 \%$ and $27 \%$ of patients, respectively. Epidural spinal cord compression scores were collected for each patient pre- and postoperatively.

CONCLUSIONS The combination of surgery and SBRT provides excellent local control following intralesional curettage and separation surgery for chordomas in the mobile spine. Patients who underwent intralesional curettage and spinal SBRT as initial treatment had better disease control than those undergoing salvage therapy. High-dose radiotherapy may offer several biological benefits for tumor control.

https://thejns.org/doi/abs/10.3171/2016.9.FOCUS16373

KEY WORDS chordoma; separation surgery; radiosurgery

$\mathrm{C}$ HORDOMA is a rare, primary spinal malignant neoplasm that arises from the remnants of the embryonic notochord. $23,50,57$ Chordoma has a reported incidence of less than 0.1 per 100,000 people per year but is the most frequent of the primary spinal tumors ${ }^{6}$ and often presents with vague, indolent symptoms. ${ }^{6,23,30}$ Given their relatively slow malignant growth, chordomas are often diagnosed late in the disease process and involve critical structures, creating challenging treatment needs for these complex cases. Physicians commonly use the Enneking

ABBREVIATIONS CTCAE = Common Terminology Criteria for Adverse Events; ESCC $=$ epidural spinal cord compression; MSKCC = Memorial Sloan Kettering Cancer Center; SBRT = stereotactic body radiation therapy. 
staging system, designed to describe primary musculoskeletal tumors, when discussing treatment and prognosis for spine tumors including chordoma. ${ }^{18}$ En bloc resection with wide margins to prevent seeding and recurrence has been advocated as the only means to achieve cure, ${ }^{6}$ whereas intralesional resection without effective adjuvant therapy has proven to be less effective for local control. .2,59,62 $^{3}$ En bloc resection is invasive and often associated with a high risk for complication, but it has proven to be effective in lengthening survival and maintaining local control better than any other method shown to date. $3,4,6,7,9,13,17,20,25,27,34$, $39,42-44,49,55$

While en bloc resection is the treatment of choice for chordoma, not all chordomas are conducive to en bloc resection to achieve marginal or wide margins due to their relationship to other vital structures such as the spinal cord or vertebral arteries. ${ }^{23,31}$ However, some authors have argued that aggressive resection is indicated even in the face of severe neurological sacrifice. With up to $32 \%$ of reported chordomas arising in the mobile spine, there remains a need to explore alternatives to traditional en bloc treatment in such complex cases with unique anatomical constraints. ${ }^{31,38}$ While traditionally thought to be the quintessential radioresistant tumor, chordomas have recently been shown to respond positively to surgery followed by adjuvant single-fraction stereotactic body radiation therapy (SBRT). ${ }^{31}$ With improved technology and the ability to define more conformal radiation margins, single-fraction SBRT provides a safer alternative for tumors not amenable to en bloc resection with wide margins while still achieving appropriate tumor control and preventing disease progression. ${ }^{31}$ We report on a single-institution series of 12 patients who underwent intralesional resection with separation surgery followed by adjuvant SBRT.

\section{Methods}

IRB approval was obtained. We identified 22 patients with a histologically confirmed diagnosis of chordoma in the mobile spine who underwent resection followed by SBRT at Memorial Sloan Kettering Cancer Center (MSKCC) from 2004 to 2016. Patients who underwent spinal SBRT within 4 months following surgery were included. Patients were considered to have undergone SBRT if they had received 5 or fewer fractions of high-dose radiation. Of the 22 patients undergoing resection, 13 met inclusion criteria of having undergone resection followed by SBRT treatment as defined above. One patient was excluded because of a lack of follow-up imaging. The remaining 12 patients were subsequently divided into two cohorts: Cohort 1 was composed of those whose initial chordoma treatment was at MSKCC and Cohort 2 was composed of those whose initial treatment was elsewhere and whose current salvage treatment was at MSKCC. Cohort 1 contained 5 patients and Cohort 2 contained 7 patients.

Patient and tumor characteristics, treatments, and follow-up information were collected through a retrospective review of a prospectively maintained database. Each patient had at least one documented imaging modality for review. For each patient, all imaging and radiology reports (CT, MRI, and plain radiography) were reviewed from the time of treatment until last follow-up for evidence of progression. Dates of all posttreatment images showing progression were noted and used for analysis of progression-free survival. Progression-free survival was defined as the time between SBRT and the next imaging modality demonstrating evidence of disease progression. Pretreatment, posttreatment, and follow-up MRI images were further reviewed to determine epidural spinal cord compression (ESCC) scores $^{5}$ at the time of treatment, immediately posttreatment, and at the time of last follow-up. Treatment complications were graded using the National Cancer Institute Common Terminology Criteria for Adverse Events (CTCAE) version 4. IBM SPSS statistical software was used to perform Kaplan-Meier analysis.

Spine SBRT was performed as previously described. ${ }^{61}$ Briefly, patients underwent simulation with CT images with 2-mm slice thickness. A myelogram or MRI fusion was used to delineate spinal cord anatomy and tumor volumes. Patients were immobilized using a patient-customized cradle for both simulation and treatment. ${ }^{60}$ Treatment planning was performed using either Top Module (MSKCC, in-house software) or Eclipse (Varian Medical Systems); we used an inverse treatment planning-typically 5-7 radiation beams around a single isocenter with intensity modulation controlled with multileaf collimators. The gross tumor volume was outlined according to $\mathrm{CT}$ and MRI images after consensus review by the treating radiation oncologist and neurosurgeon. The clinical target volume encompassed gross tumor volume and areas of potential microscopic spread. The planning target volume was a 2-mm expansion from the clinical target volume, excluding the thecal sac and also the esophagus if abutting gross tumor volume. The prescribed dose ranged from 24 Gy in 1 fraction to 24-36 Gy in 3 fractions, and the dose was prescribed to the $100 \%$ isodose line as allowed by dose constraints for organs-at-risk such as the spinal cord, esophagus, and bowels. Treatment was delivered with a LINAC (linear accelerator) using 6-mV and/or $15-\mathrm{mV}$ photons. Cone-beam CT scans were used to verify patient positioning prior to treatment.

\section{Results}

Twelve patients met the inclusion criteria. Patient and tumor characteristics are summarized in Table 1. The majority of patients were men (75\%), and the median age at surgery was 59 years (range $47-81$ years). The median time between surgery and SBRT was 40 days (range 19124 days). The median follow-up duration from SBRT was 26 months (range 1.7-89 months). Six cervical, 4 thoracic, and 2 lumbar spine tumors were treated.

Radiation treatment details are shown in Table 2. The majority of patients were treated with either 24 Gy in 1 fraction or $27 \mathrm{~Gy}$ in 3 fractions, while the remaining patients were treated in 3 fractions to a total dose ranging from 24 Gy to $36 \mathrm{~Gy}$. Four patients (33\%) received p32 plaque brachytherapy intraoperatively at the time of surgical curettage. Six patients overall (50\%), all in Cohort $2(85.7 \%)$, had received prior radiation at the site -4 received prior SBRT and 2 received prior radiation therapy with conventional fractionation. 
TABLE 1. Patient and tumor characteristics

\begin{tabular}{|c|c|c|c|}
\hline Patient Characteristics & $\begin{array}{l}\text { All Patients } \\
\quad(n=12)\end{array}$ & $\begin{array}{l}\text { Cohort } 1 \\
(n=5)\end{array}$ & $\begin{array}{c}\text { Cohort } 2 \\
(n=7)\end{array}$ \\
\hline $\begin{array}{l}\text { Age at op, median } \\
\text { (range), yrs }\end{array}$ & $59(47-81)$ & $61(56-81)$ & $59(47-78)$ \\
\hline \multicolumn{4}{|l|}{ Age group, no. (\%), yrs } \\
\hline$\leq 55$ & $1(8)$ & $0(0)$ & $2(28.6)$ \\
\hline $55-64$ & $6(46)$ & $3(60)$ & $2(28.6)$ \\
\hline$\geq 65$ & $6(46)$ & $2(40)$ & $3(42.8)$ \\
\hline \multicolumn{4}{|l|}{ Sex, no. (\%) } \\
\hline Male & $8(62)$ & $2(40)$ & $5(71.4)$ \\
\hline Female & $5(38)$ & $3(60)$ & $2(28.6)$ \\
\hline $\begin{array}{l}\text { Days btwn op \& SBRT, } \\
\text { median (range) }\end{array}$ & $40(19-124)$ & $40(22-50)$ & $40(19-124)$ \\
\hline $\begin{array}{c}\text { Mos btwn SBRT \& last } \\
\text { FU, median (range) }\end{array}$ & $37.3(1.7-89)$ & $65.4(14-89)$ & $10.7(1.7-82)$ \\
\hline \multicolumn{4}{|l|}{ Levels treated, no. (\%) } \\
\hline Cervical & $6(50)$ & $3(60)$ & $3(42.8)$ \\
\hline Thoracic & $4(33.3)$ & $1(20)$ & $3(42.8)$ \\
\hline Lumbar & $2(16.7)$ & $1(20)$ & $1(14.3)$ \\
\hline
\end{tabular}

$\mathrm{FU}=$ follow-up.

Surgical and SBRT complications are detailed in Table 3. Overall, $75 \%$ of patients experienced complications, with $41.7 \%$ experiencing CTCAE Grade 3 or higher complications. There were 2 Grade 1 toxicities, 4 Grade 2 toxicities, 4 Grade 3 toxicities, and 1 Grade 4 toxicity reported. There were no reported Grade 5 toxicities.

\section{TABLE 2. Radiation treatment characteristics}

\begin{tabular}{llll}
\hline & \multicolumn{3}{c}{ No. of Patients (\%) } \\
\cline { 2 - 4 } Radiation Characteristics & $\begin{array}{c}\text { All Patients } \\
(n=12)\end{array}$ & $\begin{array}{c}\text { Cohort 1 } \\
(n=5)\end{array}$ & $\begin{array}{c}\text { Cohort 2 } \\
(n=7)\end{array}$ \\
\hline SBRT dose \& fractionation & & & \\
\hline 24 Gy/1 fraction & $6(50)$ & $3(60)$ & $3(42.8)$ \\
\hline 24 Gy/3 fractions & $1(8.3)$ & $0(0)$ & $1(14.3)$ \\
\hline 27 Gy/3 fractions & $3(25)$ & $2(40)$ & $1(14.3)$ \\
\hline 30 Gy/3 fractions & $1(8.3)$ & $0(0)$ & $1(14.3)$ \\
\hline 36 Gy/3 fractions & $1(8.3)$ & $0(0)$ & $1(14.3)$ \\
\hline Intraop p32 plaque brachytherapy & & & \\
\hline No & $8(67)$ & $4(80)$ & $4(57.1)$ \\
\hline Yes & $4(33)$ & $1(20)$ & $3(42.8)$ \\
\hline Prior radiation at site & & & \\
\hline No & $6(50)$ & $5(100)$ & $1(14.3)$ \\
\hline Yes & $6(50)$ & $0(0)$ & $6(85.7)$ \\
\hline No. of contiguous levels treated & & & \\
w/ SBRT & & & \\
\hline 1 & $3(25)$ & $2(40)$ & $1(14.3)$ \\
\hline 2 & $1(8.3)$ & $1(20)$ & $0(0)$ \\
\hline 3 & $5(41.7)$ & $1(20)$ & $4(57.1)$ \\
\hline 4 & $3(25)$ & $1(20)$ & $2(28.6)$ \\
\hline
\end{tabular}

TABLE 3. Surgical and radiation complications

\begin{tabular}{|c|c|c|c|c|c|}
\hline \multirow[b]{2}{*}{ CTCAE } & \multirow{2}{*}{$\begin{array}{c}\text { All } \\
\text { Patients }\end{array}$} & \multicolumn{2}{|r|}{ Cohort 1} & \multicolumn{2}{|r|}{ Cohort 2} \\
\hline & & No. & Toxicity & No. & Toxicity \\
\hline Grade 1 & 2 & 1 & Compression fracture & 1 & Dermatitis \\
\hline Grade 2 & 4 & 4 & $\begin{array}{l}\text { Dysphagia, xerostomia, } \\
\text { MRI spinal cord } \\
\text { signal change, DVT }\end{array}$ & 0 & NA \\
\hline Grade 3 & 4 & 4 & $\begin{array}{l}\text { Dysphagia, mucositis, } \\
\text { hardware failure, vo- } \\
\text { cal cord paralysis }\end{array}$ & 0 & NA \\
\hline Grade 4 & 1 & 0 & NA & 1 & $\begin{array}{l}\text { Wound de- } \\
\text { hiscence }\end{array}$ \\
\hline
\end{tabular}

DVT = deep vein thrombosis; $N A=$ not applicable.

Grade 1 toxicities included dermatitis and fracture. Grade 2 toxicities included dysphagia, xerostomia, spinal cord T2 signal change on MRI, and deep vein thrombosis. Radiation-associated major complications occurred in $27 \%$ of patients, and included dysphagia, mucositis, and vocal cord paralysis that occurred 4 years after radiation therapy. Two complications directly related to surgery included a rod fracture that occurred 4 years postoperatively and a wound dehiscence after a reoperation for tumor recurrence in Cohort 2, resulting in a surgical complication frequency of $18 \%$.

Table 4 provides a summary of clinical information for each patient. Of the 5 patients in Cohort 1 , only 1 had local progression at last follow-up, resulting in a local control rate of $80 \%$ at last follow-up. Cohort 1 had a median postSBRT follow-up period of 65.9 months; Cohort 2 had a median follow-up duration of 10.7 months, with 3 patients having progression, for a local control rate of $57.1 \%$ at last follow-up.

Kaplan-Meier curves for overall survival are shown in Fig. 1. At 2 years, actuarial overall survival was $80 \%$ for Cohort 1 and $85.7 \%$ for Cohort 2. The mean actuarial estimations of overall survival were 76.6 months $(95 \%$ CI 50.1-103.2 months) and 68.6 months (95\% CI 32-104.6 months) for Cohort 1 and for Cohort 2, respectively. Analysis of combined cohort data revealed an estimated overall survival of 77.6 months (95\% CI 52-103.3 months).

\section{Illustrative Cases \\ Cohort 1}

A 57-year-old woman presented with a 6-month history of neck stiffness and hand clumsiness. She also reported a 1-month history of anterior thigh hyperesthesia but denied weakness, numbness, or vesicorectal dysfunction. MRI of the cervical spine, ordered by her primary care physician, revealed a mass involving the C-5 and C-6 vertebral bodies (Fig. 2A) with a large epidural component and severe spinal cord compression (ESCC Grade 3) with spinal cord edema. Examination revealed full strength throughout but diminished dexterity in both hands. She underwent CT-guided needle biopsy, the results of which revealed a chordoma. She was started on a course of dexamethasone and scheduled for surgery. She underwent C4-7 lami- 
TABLE 4. Radiation and surgical characteristics by patient

\begin{tabular}{|c|c|c|c|c|c|c|c|c|c|c|c|c|c|}
\hline \multirow{2}{*}{$\begin{array}{l}\text { Patient } \\
\text { No. }\end{array}$} & \multirow[b]{2}{*}{ Sex } & \multirow[b]{2}{*}{ Age } & \multirow{2}{*}{$\begin{array}{l}\text { Tumor } \\
\text { Location }\end{array}$} & \multirow{2}{*}{$\begin{array}{l}\text { No. } \\
\text { of } \\
\text { Previous } \\
\text { Ops }\end{array}$} & \multirow{2}{*}{$\begin{array}{l}\text { Previous } \\
\text { RT Gyl } \\
\text { No. of } \\
\text { Fractions }\end{array}$} & \multirow{2}{*}{$\begin{array}{l}\text { SBRT } \\
\text { Dose Gyl } \\
\text { No. of } \\
\text { Fractions }\end{array}$} & \multicolumn{3}{|c|}{$\begin{array}{l}\text { ESCC } \\
\text { Score }\end{array}$} & \multirow{2}{*}{$\begin{array}{l}\text { Time } \\
\text { to } \\
\text { Progression } \\
\text { (mos) }\end{array}$} & \multirow{2}{*}{$\begin{array}{l}\text { Overall } \\
\text { Survival } \\
\text { (mos) }\end{array}$} & \multirow{2}{*}{$\begin{array}{l}\text { Complications } \\
\text { (CTCAE Grade) }\end{array}$} & \multirow{2}{*}{$\begin{array}{l}\text { Cause } \\
\text { of } \\
\text { Death }\end{array}$} \\
\hline & & & & & & & Preop & Postop & FU & & & & \\
\hline \multicolumn{14}{|c|}{ Cohort 1} \\
\hline 1 & M & 81 & T12 & NA & NA & $27 / 3$ & 3 & $1 \mathrm{c}$ & NA & NA & 52.3 & NA & NA \\
\hline 2 & $\mathrm{~F}$ & 57 & $\mathrm{C} 4-\mathrm{C} 6$ & NA & NA & $24 / 1$ & 3 & $1 b$ & 0 & NA & 67.9 & Vocal cord paralysis (3) & NA \\
\hline 3 & $\mathrm{~F}$ & 61 & C1-C3 & NA & NA & $24 / 1$ & 3 & $1 a$ & 0 & 48.2 & 91.9 & Dysphagia (3) & NA \\
\hline 4 & $\mathrm{~F}$ & 56 & C2 & NA & NA & $24 / 1$ & 1c & $1 b$ & $1 \mathrm{a}$ & NA & 16.0 & $\begin{array}{l}\text { Dysphagia (2), xerostomia } \\
\text { (2), mucositis (3), T2 } \\
\text { cord signal change (2) }\end{array}$ & $\begin{array}{c}\text { GI hemor- } \\
\text { rhage }\end{array}$ \\
\hline 5 & M & 75 & L4 & NA & NA & $24 / 1$ & $1 \mathrm{c}$ & 0 & 0 & NA & 72.2 & $\begin{array}{l}\text { L-4 compression fracture } \\
\text { (1), rod fracture (3), } \\
\text { DVT }(2)^{*}\end{array}$ & NA \\
\hline Mean & & & & & & & & & 48.2 & 60.1 & & & \\
\hline Median & & & & & & & & & 48.2 & 67.9 & & & \\
\hline
\end{tabular}

\section{Cohort 2}

\begin{tabular}{|c|c|c|c|c|c|c|c|c|c|c|c|c|c|}
\hline 6 & M & 77 & L2 & 1 & $27 / 3$ & $24 / 1$ & 3 & $1 b$ & NA & 76.3 & 105.9 & $\begin{array}{l}\text { Wound dehiscence requir- } \\
\text { ing plastic surgery }(4)^{*}\end{array}$ & Sepsis \\
\hline 7 & M & 56 & $\mathrm{C} 4-\mathrm{C} 6$ & 2 & $74 / 40$ & $24 / 3$ & 3 & $1 \mathrm{c}$ & NA & 1.9 & 63.2 & RUE paresis (2) & Unknown \\
\hline 8 & M & 55 & T5-T7 & 1 & $36 / 3$ & $24 / 1$ & 3 & $1 a$ & $1 a$ & NA & 59.9 & $\begin{array}{l}\text { Dermatitis (1), RT myelitis } \\
\text { (1) }\end{array}$ & NA \\
\hline 9 & M & 59 & T3-T4 & 1 & $30 / 3$ & $30 / 3$ & 3 & 0 & NA & NA & 1.7 & RUE paresis (2) & Meningitis \\
\hline 10 & $\mathrm{~F}$ & 67 & T11-L1 & 5 & $17.7 / 5$ & $27 / 3$ & 3 & 3 & NA & 2.9 & 69.5 & None & NA \\
\hline 11 & M & 78 & C4-C5 & 2 & NA & $36 / 3$ & 3 & 2 & $1 b$ & NA & 27.1 & RUE paresis (2) & NA \\
\hline 12 & M & 47 & T9-T11 & 1 & $70 / 39$ & $24 / 1$ & $1 b$ & $1 \mathrm{a}$ & 0 & NA & 32.0 & None & Unknown \\
\hline Mean & & & & & & & & & & 27.0 & 51.3 & & \\
\hline Median & & & & & & & & & & 2.9 & 59.9 & & \\
\hline \multicolumn{14}{|l|}{ Overall } \\
\hline Mean & & & & & & & & & & 32.3 & 55.0 & & \\
\hline Median & & & & & & & & & & 25.6 & 61.6 & & \\
\hline
\end{tabular}

$\mathrm{GI}$ = gastrointestinal; $\mathrm{RT}$ = radiation therapy; RUE = right upper extremity.

* Indicates surgical complication.

nectomies, resection of the epidural component of the tumor, posterior C2-T2 instrumented fusion, C-5 and C-6 corpectomies, placement of a Harms titanium mesh cage (DePuy Spine), and anterior plate fixation (Fig. 3). A p32 plaque was also placed intraoperatively to deliver temporary high-dose irradiation. Her immediate postoperative ESCC grade was 1b (Fig. 2B). She had, as anticipated, selflimited mild dysphagia in the perioperative period, and her hand coordination improved. She underwent adjuvant single-fraction radiation treatment, to $24 \mathrm{~Gy}, 2$ months postoperatively. Most recent imaging, 5.25 years later, showed continued tumor control, with ESCC score of 0 (Fig. 2C). She developed delayed radiation-associated unilateral vocal cord paralysis several years postoperatively, for which she underwent a vocal cord medialization and for which symptomatic recovery was good. She remains ambulatory and had a Karnofsky Performance Scale score of 90 at last follow-up.

\section{Cohort 2}

A 78-year-old man with a history of melanoma initially presented to an outside institution with progressive right hand pain. MRI of the spine revealed a C-5 centered mass with cranial and caudal epidural extension as well as high-grade spinal cord compression. He underwent C-5 corpectomy with intralesional curettage and C3-7 laminectomies and placement of posterior instrumentation at the outside institution. Intraoperative pathological examination revealed chordoma. He was recommended radiotherapy at that time but refused, electing for observation. Five months later, MRI showed progression of his residual tumor. Subsequent MRI, then 8 months after surgery, demonstrated significant progression of disease (ESCC Grade 3 ), with encasement and displacement of the right vertebral artery, and encasement of the C-5 and C- 6 nerve roots on the right. He underwent repeat resection and decompression of the spinal cord at the same outside institution. 


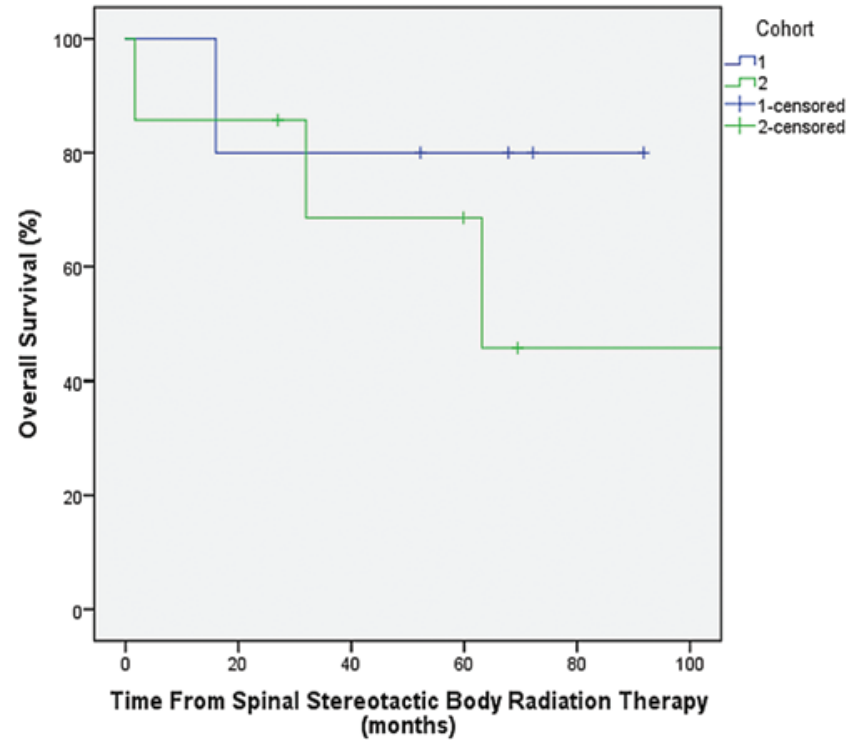

FIG. 1. Kaplan-Meier curve for overall survival for Cohorts 1 (blue) and 2 (green) after surgery followed by SBRT.

He subsequently sought care at MSKCC when his right hand pain returned and he developed proximal Grade 3/5 right upper-extremity weakness. MRI demonstrated aggressive recurrence with ESCC Grade 3 (Fig. 4A). He then underwent repeat anterior and posterior cervical resection with removal of epidural tumor and intraoperative radiation with a p32 plaque. Postoperatively his ESCC score was 2 (Fig. 4B). One month postoperatively he received SBRT (total dose 36 Gy given in 3 fractions). His most recent imaging study ( 9 months) revealed excellent tumor control with ESCC score of 1b (Fig. 4C). His proximal
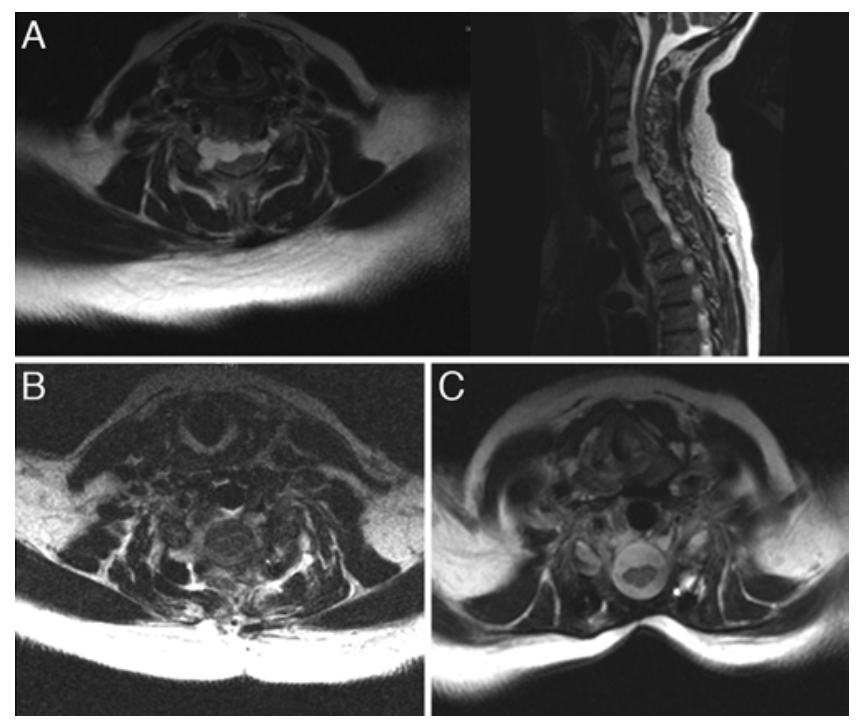

FIG. 2. Imaging for Patient 2 in Cohort 1. A: Preoperative axial and sagittal MR images demonstrating ESCC Grade 3. B: Postoperative axial MR image demonstrating ESCC Grade $1 \mathrm{~b}$. C: Long-term follow-up axial MR image demonstrating progressive resolution of chordoma, now ESCC Grade 0.
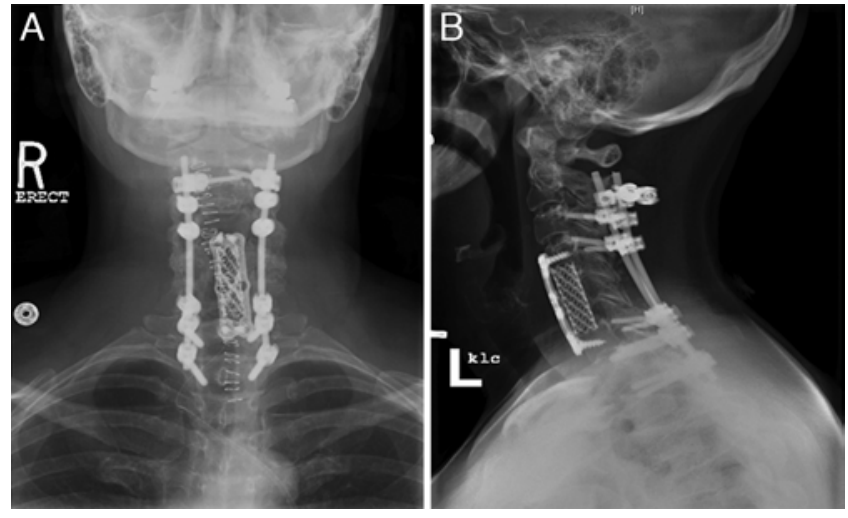

FIG. 3. Anteroposterior (A) and lateral (B) postoperative radiographs demonstrating anterior and posterior instrumented fixation.

right upper-extremity weakness did not improve and he has home health assistance.

\section{Discussion}

While data accumulate on proton ${ }^{58}$ and carbon ion radiotherapy 29,52 for treatment of chordoma, there is growing evidence for high-dose-per-fraction conformal photon irradiation as well. Single-fraction high-dose spinal radiosurgery has been shown to achieve local control in greater than $90 \%$ of metastatic tumors, even to traditionally classified radioresistant tumors such as melanoma and renal cell carcinoma. ${ }^{60}$ Additionally, several small studies have demonstrated promising results using radiosurgery for skull base chordomas, ${ }^{35-37}$ as well as mobile spine and sacral chordomas. ${ }^{61}$ Photon therapy has advantages compared with particle radiation in that it is more accessible, and spinal hardware does not diminish photon therapy efficacy while hardware does affect the efficacy of par-
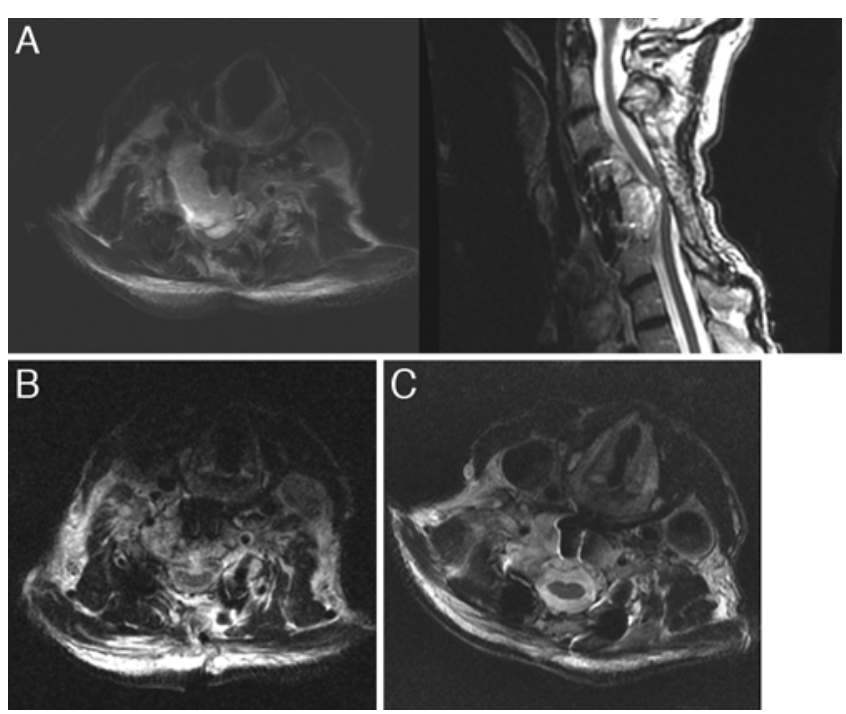

FIG. 4. Imaging for Patient 11 in Cohort 2. A: Preoperative axial and sagittal MR images demonstrating ESCC Grade 3. B: Postoperative axial MR image demonstrating ESCC Grade 2. C: Axial MR image 8 months post-SBRT demonstrating continued retraction of the tumor and ESCC $1 \mathrm{~b}$. 
ticle therapy. ${ }^{46}$ In this series we present effective control of chordoma without the use of en bloc resection with wide margins, but with curettage, intralesional resection or separation surgery followed by high-dose conformal radiation therapy. As seen in the two case examples, tumor volume decreases following intralesional surgery and high-dose SBRT as evidenced by the change in ESCC score. Patients are spared morbidity but achieve adequate tumor control. While chordomas have been considered radioresistant, the response to high-dose SBRT is encouraging. Highdose-per-fraction radiation may offer radiobiological advantages compared with conventionally fractionated radiotherapy when treating chorodmas. ${ }^{61}$ Higher doses may result in greater irreparable and lethal DNA damage ${ }^{10}$ and may also have the additional advantage of inducing tumor endothelial dysfunction, a phenomenon observed in highdose treatments. ${ }^{22}$ Additionally, high-dose-per-fraction radiation may stimulate a cytotoxic T-cell-mediated immunogenic effect, further potentiating radiotherapy. ${ }^{33}$

Molina et al. presented a multiinstitutional case series in which en bloc resection of cervical chordomas was attempted. ${ }^{40}$ Upper cervical spine (C-1 and C-2) chordomas were associated with a dramatically higher rate of complications compared with subaxial chordomas $(71 \%$ vs $22 \%$, respectively) and higher rates of recurrence. Given the complex vascular, osseoligamentous, and important neuroanatomy that presents unique surgical challenges in cases of atlantoaxial chordomas, and given the significantly higher rate of complications, the authors advocated intralesional resection for C-1 and C-2 chordomas rather than en bloc resection. Our study provides further support to their conclusion, as the one recurrence in Cohort 1 occurred in the case of a C1-3 chordoma. This patient has obtained durable control after intralesional curettage and high-doseper-fraction photon irradiation in a follow-up period of nearly 92 months. Following 48.2 months of progressionfree survival after initial surgery and SBRT, the patient then underwent a second radiation treatment in which 27 Gy of radiation was delivered in 3 fractions without further surgery, providing an additional 43.6 additional months of local control while sparing the patient the increased risk of neurological morbidity from attempted en bloc resection.

In this series, patients in Cohort 1 experienced better outcomes with a local tumor control rate of $80 \%$, while patients in Cohort 2 had a local tumor control rate of $57.1 \%$. Furthermore, among patients who had disease progression, the median time to progression was 48.2 months compared to a median of 2.9 months in Cohort 2 (Table 4). Since local control was greater than $50 \%$ in both cohorts, a median time to failure was not reached. Of those in Cohort 2 whose treatment failed, 2 of the 3 patients had rapid disease progression following treatment. Patients with chordoma often undergo multiple operations, and the first operation is the best chance at optimal outcome. ${ }^{6}$ Our data are consistent with this "first shot" principle and with Choi et al., who found that patients who had undergone prior resections at outside institutions before seeking treatment at specialized centers had lower survival rates. ${ }^{12}$

Although the possibility of "seeding" was previously described as strong evidence for en bloc resection, ${ }^{2}$ it is noteworthy that no patients in this study demonstrated re- currence along the surgical tract of the surgical wound, despite intralesional curettage surgical technique.

We found that $42 \%$ of patients had significant complications associated with surgery and radiation therapy. Surgery for primary tumors of the spine carries a significant risk of morbidity. $\mathrm{C} 1-2$ chordomas have been reported to have a $71 \%$ risk of complications..$^{40}$ The authors of a series reviewing the complications of 220 en bloc spinal operations reported that $33 \%$ of their patients had major surgical complications, with those harboring primary malignant spinal tumors having a higher risk of complications. ${ }^{8}$ One study with long-term follow-up after proton radiotherapy for chordoma noted a Grade 3-4 toxicity risk of $13 \% .^{15}$ The surgical complication frequency of $18 \%$ reported in the present series, which included a delayed rod fracture 4 years after surgery, compares favorably with the surgical complication frequency reported in other series. Furthermore, none of our patients experienced the severe neurological and systemic complication reported after en bloc surgery. Among the radiation-associated complications currently reported, 2 patients had self-limited complications and only 1 patient had a persisting complication (vocal cord paralysis). Currently used esophageal dose constraints have resulted in a significantly decreased risk of esophageal toxicity. ${ }^{14}$

In the coming era, quality of life may become an increasing consideration in the treatment of chordoma, particularly in light of potentially effective adjuvant approaches on the horizon. A focus on targeted therapy including via receptor tyrosine kinase blockade as justified by the involvement of canonical oncological mechanisms, for example via the PI3K-AKT-mTOR and RAS-MAPK pathways, has yielded some promising early reports of re-

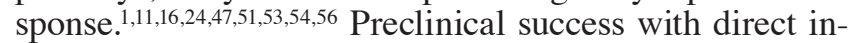
hibition of the master transcription factor brachyury has led to optimism that this may be used as a therapeutic vulnerability clinically. ${ }^{28}$ Additionally, interest in radiosensitization, vaccines, and immunotherapies, and with novel mechanistic insight from emerging from epigenetic discovery approaches, may potentially allow for future therapy abrogating the need for strategies emphasizing surgical cure via wide marginal excision. ${ }^{19,21,26,41,45,48}$

\section{Conclusions}

Intralesional debulking and separation surgery followed by SBRT for chordoma of the mobile spine provides excellent local control for patients in whom aggressive en bloc resection with wide margins is not feasible. Highdose-per-fraction irradiation may provide biological benefits compared with conventional radiotherapy. Data from our series compare favorably with those in existing literature concerning local control.

\section{Acknowledgments}

This work was supported in part by the MSKCC Support Grant (NIH/NCI P30 CA008748).

\section{References}

1. Aleksic T, Browning L, Woodward M, Phillips R, Page S, Henderson S, et al: Durable response of spinal chordoma 
to combined inhibition of IGF-1R and EGFR. Front Oncol 6:98, 2016

2. Arnautović KI, Al-Mefty O: Surgical seeding of chordomas. J Neurosurg 95:798-803, 2001

3. Bas T, Bas P, Prieto M, Ramos V, Bas JL, Espinosa C: A lumbar chordoma treated with a wide resection. Eur Spine J 3:115-117, 1994

4. Bergh P, Kindblom LG, Gunterberg B, Remotti F, Ryd W, Meis-Kindblom JM: Prognostic factors in chordoma of the sacrum and mobile spine: a study of 39 patients. Cancer 88:2122-2134, 2000

5. Bilsky MH, Laufer I, Fourney DR, Groff M, Schmidt MH, Varga PP, et al: Reliability analysis of the epidural spinal cord compression scale. J Neurosurg Spine 13:324-328, 2010

6. Boriani S, Bandiera S, Biagini R, Bacchini P, Boriani L, Cappuccio M, et al: Chordoma of the mobile spine: fifty years of experience. Spine (Phila Pa 1976) 31:493-503, 2006

7. Boriani S, Chevalley F, Weinstein JN, Biagini R, Campanacci L, De Iure F, et al: Chordoma of the spine above the sacrum. Treatment and outcome in 21 cases. Spine (Phila Pa 1976) 21:1569-1577, 1996

8. Boriani S, Gasbarrini A, Bandiera S, Ghermandi R, Lador R: Predictors for surgical complications of en bloc resections in the spine: review of 220 cases treated by the same team. Eur Spine J [epub ahead of print], 2016

9. Bosma JJ, Pigott TJ, Pennie BH, Jaffray DC: En bloc removal of the lower lumbar vertebral body for chordoma. Report of two cases. J Neurosurg 94 (2 Suppl):284-291, 2001

10. Brown JM, Koong AC: High-dose single-fraction radiotherapy: exploiting a new biology? Int J Radiat Oncol Biol Phys 71:324-325, 2008

11. Chen K, Mo J, Zhou M, Wang G, Wu G, Chen H, et al: Expression of PTEN and mTOR in sacral chordoma and association with poor prognosis. Med Oncol 31:886, 2014

12. Choi D, Melcher R, Harms J, Crockard A: Outcome of 132 operations in 97 patients with chordomas of the craniocervical junction and upper cervical spine. Neurosurgery 66:5965,2010

13. Cloyd JM, Chou D, Deviren V, Ames CP: En bloc resection of primary tumors of the cervical spine: report of two cases and systematic review of the literature. Spine J 9:928-935, 2009

14. Cox BW, Jackson A, Hunt M, Bilsky M, Yamada Y: Esophageal toxicity from high-dose, single-fraction paraspinal stereotactic radiosurgery. Int J Radiat Oncol Biol Phys 83:e661-e667, 2012

15. DeLaney TF, Liebsch NJ, Pedlow FX, Adams J, Weyman EA, Yeap BY, et al: Long-term results of Phase II study of high dose photon/proton radiotherapy in the management of spine chordomas, chondrosarcomas, and other sarcomas. J Surg Oncol 110:115-122, 2014

16. Di Maio S, Yip S, Al Zhrani GA, Alotaibi FE, Al Turki A, Kong E, et al: Novel targeted therapies in chordoma: an update. Ther Clin Risk Manag 11:873-883, 2015

17. Dubory A, Missenard G, Lambert B, Court C: "En bloc" resection of sacral chordomas by combined anterior and posterior surgical approach: a monocentric retrospective review about 29 cases. Eur Spine J 23:1940-1948, 2014

18. Enneking WF: A system of staging musculoskeletal neoplasms. Clin Orthop Relat Res (204):9-24, 1986

19. Fenerty KE, Folio LR, Patronas NJ, Marté JL, Gulley JL, Heery CR: Predicting clinical outcomes in chordoma patients receiving immunotherapy: a comparison between volumetric segmentation and RECIST. BMC Cancer 16:672, 2016

20. Fuchs B, Dickey ID, Yaszemski MJ, Inwards CY, Sim FH: Operative management of sacral chordoma. J Bone Joint Surg Am 87:2211-2216, 2005

21. Fujii R, Friedman ER, Richards J, Tsang KY, Heery CR, Schlom J, et al: Enhanced killing of chordoma cells by antibody-dependent cell-mediated cytotoxicity employing the novel anti-PD-L1 antibody avelumab. Oncotarget 7:3349833511,2016

22. Garcia-Barros M, Paris F, Cordon-Cardo C, Lyden D, Rafii $\mathrm{S}$, Haimovitz-Friedman A, et al: Tumor response to radiotherapy regulated by endothelial cell apoptosis. Science 300:1155-1159, 2003

23. Gokaslan ZL, Zadnik PL, Sciubba DM, Germscheid N, Goodwin CR, Wolinsky JP, et al: Mobile spine chordoma: results of 166 patients from the AOSpine Knowledge Forum Tumor database. J Neurosurg Spine 24:644-651, 2016

24. Han S, Polizzano C, Nielsen GP, Hornicek FJ, Rosenberg AE, Ramesh V: Aberrant hyperactivation of akt and Mammalian target of rapamycin complex 1 signaling in sporadic chordomas. Clin Cancer Res 15:1940-1946, 2009

25. Heary RF, Vaccaro AR, Benevenia J, Cotler JM: "En-bloc" vertebrectomy in the mobile lumbar spine. Surg Neurol 50:548-556, 1998

26. Heery CR, Singh BH, Rauckhorst M, Marté JL, Donahue $\mathrm{RN}$, Grenga I, et al: Phase I trial of a yeast-based therapeutic cancer vaccine (GI-6301) targeting the transcription factor brachyury. Cancer Immunol Res 3:1248-1256, 2015

27. Hsu KY, Zucherman JF, Mortensen N, Johnston JO, Gartland J: Follow-up evaluation of resected lumbar vertebral chordoma over 11 years: a case report. Spine (Phila Pa 1976) 25:2537-2540, 2000

28. Hsu W, Mohyeldin A, Shah SR, ap Rhys CM, Johnson LF, Sedora-Roman NI, et al: Generation of chordoma cell line JHC7 and the identification of Brachyury as a novel molecular target. J Neurosurg 115:760-769, 2011

29. Imai R, Kamada T, Tsuji H, Yanagi T, Baba M, Miyamoto T, et al: Carbon ion radiotherapy for unresectable sacral chordomas. Clin Cancer Res 10:5741-5746, 2004

30. Jemal A, Siegel R, Ward E, Murray T, Xu J, Thun MJ: Cancer statistics, 2007. CA Cancer J Clin 57:43-66, 2007

31. Jung EW, Jung DL, Balagamwala EH, Angelov L, Suh JH, Djemil T, et al: Single-fraction spine stereotactic body radiation therapy for the treatment of chordoma. Technol Cancer Res Treat [epub ahead of print], 2016

32. Kaloostian PE, Gokaslan ZL: Surgical management of primary tumors of the cervical spine: surgical considerations and avoidance of complications. Neurol Res 36:557-565, 2014

33. Kaur P, Asea A: Radiation-induced effects and the immune system in cancer. Front Oncol 2:191, 2012

34. Kayani B, Sewell MD, Tan KA, Hanna SA, Williams R, Pollock R, et al: Prognostic factors in the operative management of sacral chordomas. World Neurosurg 84:1354-1361, 2015

35. Krishnan S, Foote RL, Brown PD, Pollock BE, Link MJ, Garces YI: Radiosurgery for cranial base chordomas and chondrosarcomas. Neurosurgery 56:777-784, 2005

36. Lunsford LD, Niranjan A, Martin JJ, Sirin S, Kassam A, Kondziolka D, et al: Radiosurgery for miscellaneous skull base tumors. Prog Neurol Surg 20:192-205, 2007

37. Martin JJ, Niranjan A, Kondziolka D, Flickinger JC, Lozanne KA, Lunsford LD: Radiosurgery for chordomas and chondrosarcomas of the skull base. J Neurosurg 107:758-764, 2007

38. McMaster ML, Goldstein AM, Bromley CM, Ishibe N, Parry DM: Chordoma: incidence and survival patterns in the United States, 1973-1995. Cancer Causes Control 12:1-11, 2001

39. Meng T, Yin H, Li B, Li Z, Xu W, Zhou W, et al: Clinical features and prognostic factors of patients with chordoma in the spine: a retrospective analysis of 153 patients in a single center. Neuro Oncol 17:725-732, 2015

40. Molina CA, Ames CP, Chou D, Rhines LD, Hsieh PC, Zadnik PL, et al: Outcomes following attempted en bloc resection of cervical chordomas in the $\mathrm{C}-1$ and $\mathrm{C}-2$ region versus the subaxial region: a multiinstitutional experience. J Neurosurg Spine 21:348-356, 2014 
41. Moussazadeh N, Berman SH, Laufer I, Gounder M, Zheng Y, Sommer J, et al: Epigenetic profiling reveals a unique histone code in chordoma. Neurosurgery 63 (Suppl 1):208, 2016 (Abstract \#365)

42. Mukherjee D, Chaichana KL, Adogwa O, Gokaslan Z, Aaronson O, Cheng JS, et al: Association of extent of local tumor invasion and survival in patients with malignant primary osseous spinal neoplasms from the Surveillance, Epidemiology, and End Results (SEER) database. World Neurosurg 76:580-585, 2011

43. Mukherjee D, Chaichana KL, Gokaslan ZL, Aaronson O, Cheng JS, McGirt MJ: Survival of patients with malignant primary osseous spinal neoplasms: results from the Surveillance, Epidemiology, and End Results (SEER) database from 1973 to 2003. J Neurosurg Spine 14:143-150, 2011

44. Ozaki T, Hillmann A, Winkelmann W: Surgical treatment of sacrococcygeal chordoma. J Surg Oncol 64:274-279, 1997

45. Patel SS, Schwab JH: Immunotherapy as a potential treatment for chordoma: a review. Curr Oncol Rep 18:55, 2016

46. Pennicooke B, Laufer I, Sahgal A, Varga PP, Gokaslan ZL, Bilsky MH, et al: Safety and local control of radiation therapy for chordoma of the spine and sacrum: a systematic review. Spine (Phila Pa 1976) 41 (Suppl 20):S186-S192, 2016

47. Presneau N, Shalaby A, Idowu B, Gikas P, Cannon SR, Gout I, et al: Potential therapeutic targets for chordoma: PI3K/ AKT/TSC1/TSC2/mTOR pathway. Br J Cancer 100:14061414,2009

48. Rhomberg W, Eiter H, Böhler F, Dertinger S: Combined radiotherapy and razoxane in the treatment of chondrosarcomas and chordomas. Anticancer Res 26:2407-2411, 2006

49. Ruggieri P, Angelini A, Ussia G, Montalti M, Mercuri M: Surgical margins and local control in resection of sacral chordomas. Clin Orthop Relat Res 468:2939-2947, 2010

50. Samson IR, Springfield DS, Suit HD, Mankin HJ: Operative treatment of sacrococcygeal chordoma. A review of twentyone cases. J Bone Joint Surg Am 75:1476-1484, 1993

51. Schwab J, Antonescu C, Boland P, Healey J, Rosenberg A, Nielsen $\mathrm{P}$, et al: Combination of PI3K/mTOR inhibition demonstrates efficacy in human chordoma. Anticancer Res 29:1867-1871, 2009

52. Serizawa I, Imai R, Kamada T, Tsuji H, Kishimoto R, Kandatsu S, et al: Changes in tumor volume of sacral chordoma after carbon ion radiotherapy. J Comput Assist Tomogr 33:795-798, 2009

53. Stacchiotti S, Marrari A, Tamborini E, Palassini E, Virdis E, Messina A, et al: Response to imatinib plus sirolimus in advanced chordoma. Ann Oncol 20:1886-1894, 2009

54. Stacchiotti S, Tamborini E, Lo Vullo S, Bozzi F, Messina A, Morosi C, et al: Phase II study on lapatinib in advanced EGFR-positive chordoma. Ann Oncol 24:1931-1936, 2013

55. Sundaresan N, Steinberger AA, Moore F, Sachdev VP, Krol G, Hough L, et al: Indications and results of combined anterior-posterior approaches for spine tumor surgery. J Neurosurg 85:438-446, 1996

56. Tamborini E, Virdis E, Negri T, Orsenigo M, Brich S, Conca E, et al: Analysis of receptor tyrosine kinases (RTKs) and downstream pathways in chordomas. Neuro Oncol 12:776789,2010
57. Tzortzidis F, Elahi F, Wright D, Natarajan SK, Sekhar LN: Patient outcome at long-term follow-up after aggressive microsurgical resection of cranial base chordomas. Neurosurgery 59:230-237, 2006

58. Wagner TD, Kobayashi W, Dean S, Goldberg SI, Kirsch DG, Suit HD, et al: Combination short-course preoperative irradiation, surgical resection, and reduced-field high-dose postoperative irradiation in the treatment of tumors involving the bone. Int J Radiat Oncol Biol Phys 73:259-266, 2009

59. Wang Y, Xiao J, Wu Z, Huang Q, Huang W, Zhu Q, et al: Primary chordomas of the cervical spine: a consecutive series of 14 surgically managed cases. J Neurosurg Spine 17:292-299, 2012

60. Yamada Y, Bilsky MH, Lovelock DM, Venkatraman ES, Toner S, Johnson J, et al: High-dose, single-fraction imageguided intensity-modulated radiotherapy for metastatic spinal lesions. Int J Radiat Oncol Biol Phys 71:484-490, 2008

61. Yamada Y, Laufer I, Cox BW, Lovelock DM, Maki RG, Zatcky JM, et al: Preliminary results of high-dose singlefraction radiotherapy for the management of chordomas of the spine and sacrum. Neurosurgery 73:673-680, 2013

62. Yao KC, Boriani S, Gokaslan ZL, Sundaresan N: En bloc spondylectomy for spinal metastases: a review of techniques. Neurosurg Focus 15(5):E6, 2003

\section{Disclosures}

Dr. Yamada is a consultant for Varian Medical Systems and on the Speakers' Bureau of the Institute for Medical Education. Dr. Laufer receives consulting fees from DePuy/Synthes, SpineWave, and Globus. Dr. Bilsky receives consulting fees from DePuy/Synthes, Globus, and BrainLab. Dr. Lis reports being a consultant for Medtronic.

\section{Author Contributions}

Conception and design: Bilsky, Yamada, Schmitt, Laufer. Acquisition of data: Bilsky, DT Lockney, Shub, Hopkins, Lis, Yamada, Higginson. Analysis and interpretation of data: Bilsky, DT Lockney, Hopkins, NA Lockney, Lis, Schmitt, Higginson, Laufer. Drafting the article: DT Lockney, Hopkins, NA Lockney, Moussazadeh, Laufer. Critically revising the article: Bilsky, DT Lockney, Shub, Hopkins, NA Lockney, Moussazadeh, Schmitt, Laufer. Reviewed submitted version of manuscript: all authors. Approved the final version of the manuscript on behalf of all authors: Bilsky. Statistical analysis: DT Lockney, NA Lockney, Laufer. Administrative/technical/material support: Bilsky. Study supervision: Bilsky, Laufer.

\section{Supplemental Information \\ Videos \\ Video abstract. https://vimeo.com/194713781.}

\section{Correspondence}

Mark Bilsky, Department of Neurological Surgery, Memorial Sloan Kettering Cancer Center, 1275 York Ave., New York, NY 10065. email: bilskym@mskcc.org. 